\title{
9-Sentences, maximes et proverbes Mantchoux et Mongols adlı eserdeki Mançu atasözleri
}

\section{Uluhan ÖZALAN}

APA: Özalan, U. (2022). Sentences, maximes et proverbes Mantchoux et Mongols adl eserdeki Mançu atasözleri. RumeliDE Dil ve Edebiyat Araştırmaları Dergisi, (26), 155-172. DOI: 10.29000/rumelide.1073873.

Öz

Mançular Çin’i yöneten son hanedan olan Çing Hanedanını (1644-1911) kuran Tunguz topluluğudur. Yarı göçebe savaşçılar olan Mançular Çin’i idareleri altına aldıktan kısa bir süre sonra yoğun bir şekilde Çin kültüründen etkilenmeye başlamışlardır. Kültürün bütün alanlarında görülen bu Çin etkisi en çok da dil ve edebiyat alanlarında kendini göstermektedir. Bu bakımdan Mançulardan kalan eserlerin önemli bir bölümü Çinceden yapılan çevirilerdir. Mançulara ait olan eserler daha çok okçuluk, at yetiştiriciliği gibi askerî alanla ilgili kaynaklar, tarih kayıtları ve özellikle Şamanizm ile alakalı halk edebiyatı ürünleridir. Bunlardan başka farklı kaynaklarda kayıt altına alınmış birçok Mançu atasözü de vardır. Bu makalenin konusu Türkiye'de pek bilinmeyen Mançu atasözleridir. Çalışmada, Rochet tarafından 1875'te yayımlanan Sentences, Maximes Et Proverbes Mantchoux Et Mongols başlıklı kitabın "Mançu atasözleri” bölümünde yer alan 165 atasözü Türkçeye tercüme edilerek konularına göre sınıflandırılmıştır. Söz konusu kaynakta verilen atasözlerinin bir kısmının Konfüçyüs'ün özlü sözlerinin Mançucaya çevirisi olduğunu belirtmekte yarar vardır. Bu bakımdan, çalışmada ele alınan Mançu atasözleri, Konfüçyüs’ün özlü sözleri ile karşılaştırılarak hangilerinin Çin kültürü etkisiyle Mançucada görülmeye başladı̆̆ı tespit edilmeye çalışılmıştır. Ayrıca Mançu atasözlerinin yapısına dair tespitler sonuç bölümünde sunulmuştur. Çalışmanın diğer bir amacı da Mançu atasözlerini ortaya koyarak “Altay dilleri” konuşan milletlerin atasözleri üzerinde daha sonra yapılacak karşılaştırmalı ve geniş kapsamlı çalışmalara zemin hazırlamaktır.

Anahtar kelimeler: Mançular, Mançuca, Mançu atasözleri, Altayistik

\section{Manchu proverbs found in "Sentences, maximes et proverbes Mantchoux et Mongols"}

\begin{abstract}
Manchus are the Tungusic community who established the Qing Qynasty (1644-1911), the last imperial dynasty of China. Being semi-nomadic warriors, Manchus exposed to heavy influence of Chinese culture soon after they had begun ruling China. This Chinese influence, which could be observed in all cultural elements, is most visible in the domains of language and literature. In this respect, most of the literary works by Manchus are translations from Chinese. The original works are mostly related to military arts such as archery and horse breeding, folk literature works related to Shamanism. Apart from those, there are many Manchu proverbs recorded in different sources. The focus of the present paper is the Manchu proverbs, which are not known in Turkey at all. The Manchu proverbs presented in Sentences, Maximes Et Proverbes Mantchoux Et Mongols by Rochet (1875) under the title of "Manchu Proverbs" have been translated into Turkish and classified on the basis of
\end{abstract}

Dr. Öğr. Üyesi, Bolu Abant İzzet Baysal Üniversitesi, Fen Edebiyat Fakültesi, Eski Türk Dili ABD (Bolu, Türkiye), ozalan_u@ibu.edu.tr, ORCID ID: 00oo-0002-9865-6010 [Araştırma makalesi, Makale kayıt tarihi: 06.01.2022-kabul tarihi: 20.02.2022; DOI: 10.29000/rumelide.1073873]

Adres

RumeliDE Dil ve Edebiyat Araşturmaları Dergisi Osmanağa Mahallesi, Mürver Çiçeği Sokak, No:14/8 Kadıköy - ISTANBUL / TÜRKIYE 34714 e-posta: editor@rumelide.com tel: +90 505 7958124, +90 2167730616

Address

RumeliDE Journal of Language and Literature Studies

Osmanağa Mahallesi, Mürver Çiçeği Sokak, No:14/8

Kadıköy - ISTANBUL / TURKEY 34714

e-mail: editor@rumelide.com,

phone: +90 5057958124 , +90 2167730616 
their themes. Some of these proverbs found in the abovementioned source are direct translations of Confucius's analects. In order to determine whether each proverb appeared through Chinese influence, they were compared with Confucius's analects. The evaluations on the structure of the proverbs have been presented in the conclusion part. Another aim of the study is to present Manchu proverbs and form a basis for comparative studies on the proverbs of the communities who speak "Altaic Languages"

Keywords: Manchus, the Manchu language, the Manchu proverbs, Altaistic

\section{Giriş}

Mançular, Çin’i yöneten son hanedan olan Çing Hanedanını (1644-1911) kuran Tunguz topluluğudur. Dilleri tipolojik olarak “Altay dilleri” ailesinin bir üyesi olarak kabul edilen Mançular, Çin’i fethettikten kısa bir süre sonra yoğun bir biçimde Çin kültürünün etkisi altında kalmaya başlamışlardır. Çin’de yönetime geçtikleri bu dönemde, Mançuların toplam nüfusunun üç yüz bin civarında olduğu tahmin edilirken Çinli nüfusunun ise üç yüz milyona yaklaşmakta olduğu düşünülmektedir (Gorelova 2002: 8). Göçebe savaşçılar olan Mançuların, kendi kültürlerine göre oldukça köklü bir yerleşik hayat tarzı ile yazı dili ve felsefe geleneği olan Çin kültüründen etkilenmeleri kaçınılmaz olmuştur. Ayrıca, Mançucanın ülke yönetimi için gerekli olan siyasî, idarî ve bilimsel terminolojiden yoksun olmasının bu dil üzerinde Çince etkisinin oldukça yoğun bir şekilde görülmesine yol açtı̆̆ ifade edilen bir durumdur. Bu etkilenme sadece bürokratik alanla sinırlı kalmamıştır. İki topluluğun gündelik hayatta da iletişim durumunda olmaları Çince etkisinin gündelik dilde de görülmesine zemin hazırlamıştır (Stary 1994: 470).

Mançular Çing Hanedanını kurdukları dönemde Moğollarla yakın temas halinde oldukları için Moğolcayı ve Moğol yazısını biliyorlardı (Rachewilts ve Rybatzki 2010: 270). Bu sebeple Nurhaci başa geldiği ilk dönemde resmî yazışmalar Moğolca yapılmaktaydı. Ancak, Nurhaci’nin Mançu dilinin yazıya geçirilmesi için Moğol yazısına dayanan bir yazı sistemi geliştirilmesi hususunda emir verdiği bilinmektedir. Moğol alfabesinde bazı değişiklikler yapılarak geliştirilen bu yazı 1632 yılına kadar kullanılmıştır. Bu tarihte, Mançu yazısına birtakım ayırt edici işaretler eklenerek ses bilgisi belirsizlikleri giderilmiştir (Norman 2003: 485).

17. yüzyılın sonlarından itibaren Mançuca üzerinde Çincenin etkisi iyice görülmeye başlanmasıyla Mançu hanedanı mensupları dillerini korumak için bazı önlemler almışlardır. Bu amaç doğrultusunda, Mançuca birçok metin ve sözlük yayımlanmıştır. Özellikle Mançu imparatorlarından Kangxi (16621722) ve Qianlong (1736-1795) döneminde Mançucanın konuşulması teşvik edilmiştir (Crossley 1990: 28). Ancak bu girişimler Mançucanın yaşatılması için yeterli olmamış ve 18. yüzyıldan başlayarak Mançuca konuşanların sayısı azalmaya başlamış, 19. yüzyılın başlarında ise Pekin'de ve Çin'deki diğer Mançu garnizonlarında Mançuca neredeyse tamamen ortadan kalkmıştır. Ancak, Mançuca Mançurya'da yaşamaya devam etmiştir. 20. yüzylın başlarında da kuzeydoğu Mançurya'da Mançuca konuşan önemli bir nüfus olduğu belirtilmektedir (Norman 2003: 486).

Juha Janhunen, Mançuca konuşabilen kişilerin sayısının tam olarak bilinmediğini, kendini Mançu olarak tanımlayan etnik topluluk içinde Mançuca konuşurların sayısının çok az ve bunların daha çok yaşlı bireyler olduğunu belirtir (2005: 45). Son dönemde, Mançu kültürü ve diline karşı artan bir ilgi gözlemlense de Mançucanın tekrar bir konuşma dili hâline gelmesi pek mümkün görünmemektedir (Janhunen 2005: 53). Fakat Mançucayla yakın bir dil olan Sibece çoğunluğu Doğu Türkistan'da yaşayan Sibeler tarafından günümüzde de konuşulmaktadır (Janhunen 1996: 49).

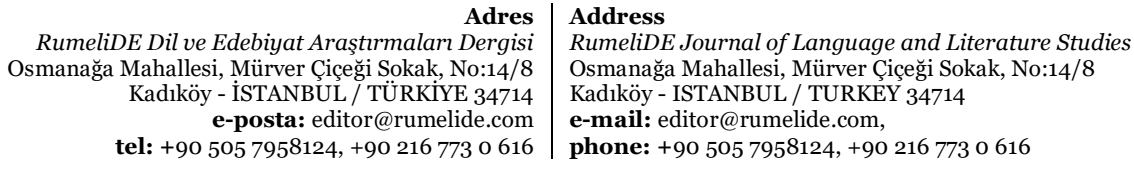


Yukarıda bahsedilen yoğun Çin etkisi, dil ve edebiyat başta olmak üzere, Mançu kültür hayatının bütün alanlarında görülmüştür. Bu sebeple bugün elimizde olan Mançuca eserlerin önemli bir bölümü aslında Çinceden yapılan tercümelere dayanmaktadır. Bu tercümelerin dışında Mançulara ait olan eserler daha çok tarih kayıtları, askerlik sanatıyla ilgili kaynaklar, özellikle Şamanizm ile ilgili bazı halk edebiyatı ürünleri ve sözlüklerdir. Möllendorff (1890:3) Mançulardan kalan eserleri şu şekilde sınıflandırır:

1. Mançuca öğretmek amaçlı yazılan kitaplar

2. Sözlükler

3. Devlet yönetimi ile ilgili kitaplar

4. Felsefe ve etikle ilgili kitaplar

5. Dinî kitaplar

6. Tarih ve coğrafya kitapları

7. Yarlıklar, anlaşma metinleri, kanunnameler

8. Askerî bilimlerle ilgili kitaplar

9. Matematik ve tıp kitapları

10. Romanlar ve şiirler

Stary, Mançu edebiyatını üç döneme ayırır: a) Klasik Mançu edebiyatı, b) Modern Mançu edebiyatı, c) Mançu-Sibe Edebiyatı (1987: 287-288). Klasik Mançu edebiyatından kalan düz yazı ve şiir türünde edebî eserler mevcuttur. Ayrıca yine bu döneme ait olan atasözleri, beyitler ve tekerlemelerden başka Budizm, Taoizm, Hristiyanlık ve Şamanizm ile ilgili eserler vardır. Çing hanedanın yıkılmasından günümüze kadar olan dönem Modern Mançu edebiyatı dönemi olarak kabul edilir. Eserlerinde Mançuca kullanmaya devam eden yazarlar tarafından yazılan bazı şiirler ve Mançuca olarak basılan gazeteler Modern Mançu edebiyatının eserleri olarak değerlendirilir. Sibeler tarafından üretilen edebî eserler de Mançu-Sibe edebiyatı dönemine dâhil edilir (Stary 1987: 289-295) ${ }^{2}$.

Bugün için elimizde olan Mançu halk edebiyatı ürünlerinin sayısının çok olduğu söylenemez. Tunguz dillerinin ve Mançuca ile Mançucanın tarihî kolu olarak değerlendirilen Cürçencenin nispeten geç dönemlerde yazıya geçirilmesi, bu toplulukların yoğun bir şekilde Çin kültüründen etkilenmiş olmaları bu durumun sebepleri olarak düşünülebilir. Mançulara ait en önemli halk edebiyatı ürünü olan Nişan Şaman Hikâyesinin "Altay dillerine" ait eserlerden, üzerinde en çok çalışma yapılan metinlerden olduğu ifade edilmektedir (Stary 1990: 317). Bundan başka, Mançu Şamanizm’ine ait bazı dualar, şarkılar Mançulardan kalan diğer halk edebiyatı ürünleridir (Stary 2002: 167). Ayrıca farklı kaynaklarda kayıt altına alınmış olan çok sayıda Mançu atasözü de günümüze ulaşmıştır.

2 CCalışmanın merkezinde doğrudan Mançu edebiyatı olmadığı için konunun ayrıntılarına burada girilmeyecektir. Konuyla ilgili ayrıntılı bilgi için Stary 2005'e bakılabilir.

RumeliDE Dil ve Edebiyat Araştırmaları Dergisi Osmanağa Mahallesi, Mürver Çiçeği Sokak, No:14/8 Kadıköy - İSTANBUL / TÜRKIYE 34714 e-posta: editor@rumelide.com tel: +90 505 7958124, +902167730616

Address

RumeliDE Journal of Language and Literature Studies

Osmanağa Mahallesi, Mürver Çiçeği Sokak, No:14/8

Kadıköy - ISTANBUL / TURKEY 34714

e-mail: editor@rumelide.com,

phone: +90 $5057958124,+90216773$ o 616 


\section{Mançu atasözleri}

Sözlü kültür ürünlerinden biri olan atasözlerine Mançucada an i gisun "genel, yaygin söz" (Norman 2013: 18) veya dekdeni gisun “özlü söz, deyiş” (Hauer 2007: 100) denmektedir. Atasözlerinin bir milletin kültürünü, hayata bakışını ve varlıkla olan ilişkisini kısa ve etkili ifade biçimleriyle ortaya koyduğu bilinmektedir. Dolayısıyla Mançuları tanımak, geçirdikleri kültürel aşamaları anlamak, bunun ötesinde "Altay dilleri” konuşan milletlerin kültürel yönden ne şekilde birbirine benzediğini ortaya koymak için Mançu atasözleri oldukça değerli veriler sunmaktadır³. Bu çalışmada ele aldığımız atasözleri, Rochet tarafından yayımlanan Sentences, Maximes Et Proverbes Mantchoux Et Mongols adlı kitabın "Mançu atasözleri” bölümünde yer almaktadır4. Rochet, çalışmasının giriş bölümünde Mançu atasözlerinin bir kısmını Klaproth'un Chrestomathie Mandchou ou Recueil De Textes Mandchou adlı kitabından ve bazı Mançuca kaynaklardan aldığını ifade eder (1875 II). Atasözü olarak verilen bu örneklerin bir kısmı aslında Konfüçyüs'ün öğretilerinin Mançucaya çevirisidir5. Yukarıda da ifade edildiği gibi, Çin kültürünün bütün unsurlarından yoğun bir biçimde etkilenen Mançular devlet yönetiminde de Konfüçyüs geleneğini benimsemişlerdir (Elliot 2001: 28). Bu bakımdan, aslında Mançu kültürüne ait olmayan bazı özlü sözlerin, kültür etkileşimi sonucunda Mançu atasözleri olarak kabul edildiğini söylemek mümkündür. Çalışmada ele alınan atasözlerinden hangilerinin bu nitelikte olduğunu tespit edebilmek için Mançu atasözleri, Eno 2015’te verilen Konfüçyüs’ün öğreti niteliğindeki özlü sözleri ile karşılaştırılmıştır. Bir Mançu atasözünün Konfüçyüs’ün sözü ile örtüşmesi durumunda, atasözünün denk geldiği özlü sözün Eno 2015’teki numarası, Mançu atasözünün Türkçeye çevirisinden sonra, parantez içinde gösterilmiştir. Çalışmada öncelikle Mançu atasözleri konularına göre sınıflandırılmıştır. $\mathrm{Bu}$ atasözlerinin yapısına dair tespitler sonuç bölümünde verilmiştir. Çalışmanın öncelikli amacı Mançu atasözlerini ortaya koyarak Mançu kültürünü tanıtmak ve "Altay dilleri” konuşan milletlerin atasözleri üzerinde yapılacak karşılaştırmalı çalışmalara zemin oluşturmaktır. Bundan dolayı, Mançu atasözleri Türk veya Moğol atasözleri ile yapı veya anlam bakımından karşılaştırılmamıştır.

\section{Konularına göre Mançu atasözleri}

Çalışmada ele alınan atasözleri konularına göre I. Bilgi, bilgelik, eğitim ve erdemle ilgili atasözleri, II. Aile ve aile bireyleri arasındaki ilişkilerle ilgili atasözleri, III. Toplumsal ilişkiler ve olaylarla ilgili atasözleri, IV. Devlet görevlileri ve devlet yönetimiyle ilgili atasözleri, V. Hayata, insana dair gözlem ve tespitlerle ilgili öğüt niteliğinde atasözleri olarak sınıflandırılmıştır. Ancak bu çalışmada bütün Mançu atasözlerinin değerlendirme konusu yapılmadığı vurgulanmalıdır.

Atasözlerinin sınıflandırılması konusunda araştırmacılar tarafından farklı yöntemler teklif edilmiştir. Bu konuda genel olarak kabul görmüş bir yöntem geliştiren Matti Kuusi, atasözlerinin on üç temel başlık altında değerlendirilebileceğini belirtir. Bu temel başlıklar şunlardır; 1. Pratik doğa bilgisi, 2. İnanç ve basit inanışlar, 3. Temel gözlemler ve sosyo-mantık, 4.Dünya ve insan hayatı, 5. Paylaşım durumu, 6. Maneviyat/ ahlâk, 7. Sosyal yaşam, 8. Sosyal etkileşim, 9. İletişim, 10. Sosyal konum, 11. Anlaşmalar ve kaideler, 12. Üstesinden gelme ve öğrenme, 13. Zaman ve zamanın anlamı (bk. Meider 2004: 16-17, Gül 2010: 42-44). Aksoy, kavramsal değerleri bakımından Türk atasözlerini uzun bir gözlem sonucu tabiat olaylarının nasıl olageldiklerini ifade eden, uzun bir gözlem ve deneme sonucu olarak sosyal olayların nasıl olageldiklerini tarafsızca bildiren, uzun bir gözlem ve deneme sonucu sosyal olayların nasıl

\footnotetext{
Bu bağlamda, Prof. Dr. Bülent Gül (2010) tarafından "Moğol Atasözleri” başlıklı çalışmada sunulan veriler, yapılacak karşılaştırmalı çalışmalar için oldukça önemlidir. Ayrıca, Türklerde atasözü yazıcılığının tarihî gelişimi ve bu süreçte kayıt altına alınan atasözleri için Durmuş 2020’ye bakılabilir.

Stary 1986 ve Stary 2012, Mançu atasözleri bakımından diğer önemli kaynaklardır.

Benzer şekilde, Kore atasözlerinde de Konfüçyüs geleneğinin etkilerini görmek mümkündür (Lee 2017: 3). Adres | Address

RumeliDE Dil ve Edebiyat Araştrmaları Dergisi $\quad$ RumeliDE Journal of Language and Literature Studies Osmană̆a Mahallesi, Mürver Ciçeği Sokak, No:14/8 $\quad$ Osmanağa Mahallesi, Mürver Çiçeği Sokak, No:14/8 Kadıköy - ISTANBUL / TURKIYE 34714 Kadıköy - ISTANBUL / TURKEY 34714 e-posta: editor@rumelide.com $\quad$ e-mail: editor@rumelide.com, tel: +90 $5057958124,+902167730616$ phone: +90 505 7958124, +90 2167730616
} 
olageldiklerini bildirirken bundan bir ders almamızı (açıç̧a söylemeyip dolayısıyla) hatırlatan, denemelere ve mantığa dayanarak doğrudan doğruya ahlâk dersi ve öğüt veren, bazı gerçekler, felsefeler ve bilgece düşünceler bildirerek yol gösteren, töreleri ve gelenekleri bildiren, bazı inanışları bildiren atasözleri olarak sınıflandırır (1971: 21-22). Çalışmamızda Mançu atasözleri konularına göre beş başlık altında değerlendirilmiştir. Fakat Mançu atasözleri üzerine yapılacak daha kapsamlı çalışmalarda bu konu başlıklarının sayısının artacağı da muhakkaktır. Bununla birlikte aşağıda verilen bazı Mançu atasözlerinin birden fazla kategoriye dâhil edilmesi mümkündür. Ancak bu nitelikteki atasözleri farklı başlıklar altında tekrarlanmayıp sadece bir başlık altında değerlendirilmiştir.

\section{Bilgi, bilgelik, eğitim ve erdemle ilgili atasözleri}

İncelediğimiz eserde verilen Mançu atasözlerinin önemli bir bölümü bilginin önemi ile ilgilidir. Ayrıca erdemli olma, eğitime değer verilmesi gerektiği birçok atasözünde vurgulanmıştır. Bu başlık altında değerlendirilen atasözlerinin bir kısmını Konfüçyüs'ün özlü sözlerinin Mançucaya çevirisi oluşturmaktadır.

tacire de amurangge, mergen de hanci, girure be sarangge, baturu de hanci "Öğrenmeyi seven bilginlere yakındır, utanmayı bilen cesurlara yakındır"

julgei tacirangge, beyei jalin te i tacirangge, niyalmai jalin "Önceden aldığın eğitim kendin içindir, şimdi aldığın eğitim başkaları içindir"

ambasa saisa elehun i ler ler sembi buya niyalma enteheme hir hir sembi "Bilge kişiler dingin ve sakindir, sıradan kişi her zaman huzursuzdur"

taidz tacikū de dosika manggi, geren irgen i emu adali "Şehzade sınıfa girdikten sonra diğer insanlarla eşit olur”

ambasa saisa absi ocibe, beye elehun akūngge akū "Bilge kişiler ne olursa olsun kendilerini yeterli görmezler"

fe be uribumbime ice be sarangge sefu oci ombidere "Eskiyi ykkarak yeniyi öğrenen kişi hoca olmuştur"

ulhire i hūdun ningge be, mergen sembi, sara i farhūn ningge be, mentuhun sembi "Hızlı anlayana akıllı denir, bilgisi bulanık olana aptal denir"

tacimbime, gūnirakū oci, mekele ombi, gūnimbime, tacirakū oci, jecukuri ombi "Öğrendiklerimizi düşünmezsek boşa gider, öğrenmeden düşünmek kafayı karıştırır”

tacire de amurangge, mergen de hanci “Öğrenmeyi seven bilgelere yakın olur”

erde doro be donjifi, yamji bucecibe ombikai "Sabah doğruyu duyduktan sonra akşam ölsem de gam yemem" (4:8)

sure genggiyen ulhisu mergen gūwa niyalma ci fulu ombi “Akıllı, zeki ve bilge bir kişi diğer insanlardan üstündür”

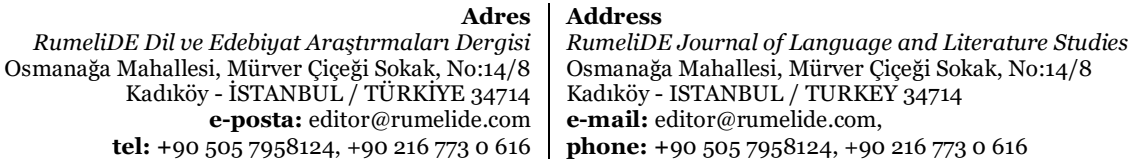
tel: +90 505 7958124, +90 2167730616

. editor@rumelide.com

phone: +90 $5057958124,+902167730616$ 
mergen be sabuci, jergilere be gūni, mergen akūngge be sabuci, dolori beyede kimci "Akıllı birini görürsen onun gibi olmaya çalış, akılsız birini görürsen onda kendini sorgula"

ambasa saisa jurgan be sambi, buya niyalma aisi be sambi "Bilge kişi erdemi bilir, sıradan kişi çıkarlarını bilir”

erdemu be wesihun oburengge saisa be huwekiyeburengge kai "Erdemi yücelten kişi bilgelere örnek olur"

erdemu emteli akū, urunakū duwali bi “Erdem yalnız değildir, her koşulda bir yoldaşı olur” (4:25)

ambasa saisa mohocibe akdun, buya niyalma mohoci, uthai balai ombi "Bilge kişiler yokluğa düşse de sağlam durur, sıradan kişiler yokluğa düşse hemen bozulur" (15:2)

ambasa saisa beye de baimbi, buyu niyalma, beye de baimbi "Bilge kişiler kendini sorgular, sıradan kişiler başkalarını sorgular" (15:21)

doro be gūni, bi, erdemu be memerembi, gosin de nikembi, muten de saşambi “Töreyi düşün, erdemden ayrilma, sevgiye güven, sanattan zevk al"

foutze hendume, bi, erdemu be buyerengge, boco be buyere adalingge be sabure unde "Efendi şöyle söyler; Ben erdemi cinsel ilişki kadar seven bir kimseyi henüz görmedim” (15:13)

ambasa saisai erdemu oci, edun, buya niyalma edun oci, orho, orhoi dele edun daci urunakū neihūmbi "Bilge kişiler özü itibarıyla rüzgâr gibidir, sıradan kişiler özü itibarıyla çimen gibidir, rüzgâr estiğinde çimenler eğilir” (12:19)

tze gung, ambasa saisa be fonjire jakade, fudzi hendume, gisun i onggolo yabufi, amala dahabumbi "Zi Gong "Bilge kimdir?" diye sorduğunda Efendi şöyle dedi; Telkin ettiği şeyi önce kendisi yapan, sonra da ona uyandır" (2:13)

erdemu bisirele gucu be gucule, tusa akū gucu be ashū "Erdemli kişilerle arkadaşlı et, yararsız kişilerden uzak dur"

ambasa saisa, jalin tuhentele gebu tukirakū be ubiyambi "Bilge bir kişiyi adının sonraki kuşaklara ulaşmama düşüncesi üzer”

ambasa saisa erdemu be gūnin de tebumbi "Bilge kişiler erdemi düşüncelerinde konumlandırır"

enduringge niyalmai bithe be hūlaci tetendere, urunakū doro giyan be saci acambi "Azizlerin kitaplarını okuyup anlamak istiyorsan gelenekleri ve ilkeleri bilmen gerekir"

tacire ursei bithe hülarangge umai hafan oki serengge waka, cohome doro be getukeleki sere gūnin "Aydın kişilerin kitaplarını okuyanların amacı yüksek mevkili idareci olmak değildir, ilkeleri düşüncelerinde daha iyi anlamaktır"

banin ishunde hanci, tacin ishunde goro "İnsanlar özünde birbirine yakındır, aldıkları eğitim onları birbirinden uzaklaştırır"

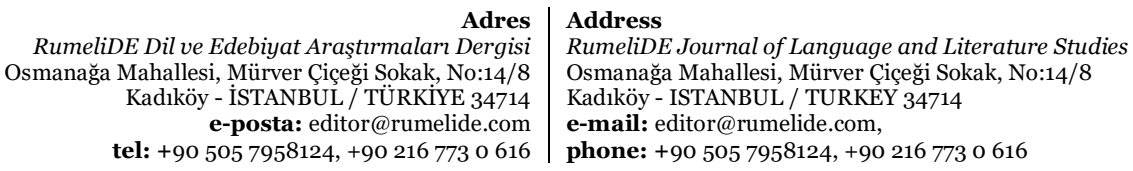


niyalma oki seci jirgara be bairakū, jirgara be baiki seci niyalma ojorakū "İnsan olmak istiyorsan durup dinlenme, durup dinlenmek isteyen insan olamaz"

kung fudzi, doro be yabuha de, emu inenggi sidende bolgo ombi "Efendi Kung'un yolundan gitmek için bir gün boyunca namuslu olmak gerekir"

\section{Aile ve aile bireyleri arasındaki ilişkilerle ilgili atasözleri}

Aile büyüklerine saygı gösterilmesinin Mançu kültüründeki önemi Mançu atasözlerine de yansımıştır. Ayrıca ailedeki bireylerin birbirlerine karşı sorumluluğu atasözlerinde işlenen bir konudur.

ama eme i se be, gūnirakū oci ojoraku, emu de oci urhunjembi, emu de oci jobombi "Anne babamızın yaşını düşünmezsek olmaz, bu bizi hem sevindirir hem de korkutur"

foutze hendume, ama bisire de, terei mujin be tuwambi, ama akū oho de terei yabun be tuwambi, ilan aniya otolo, ama i doro be halarakū oci, hiyooşungga seci ombidere "Efendi şöyle söyler; Baban hayattayken onun niyetini gözlemle, öldükten sonra onun yapmış olduklarını yap, eğer üç yıla kadar babanın yolundan ayrilmazsan, sen hakiki bir evlatsın” (1:11)

sargan mergen oci eigen de gasacun komso, jui hiyooşungga oci ama i mujilen sulfa "Karısı zeki ise kocanın sıkıntısı az olur, oğlu hayırlı ise babanın yüreği ferah olur"

boo yadahūn ohode hiyooşungen jui be sambi, gurun facuhūn ohode tondo amban be takambi "Hayırlı oğul ev yoksullaşınca anlaşılır, sadık bir hizmetkâr ülke sıkıntıya düşünce anlaşılır"

kemuni husun buhe aha be gūni, faşşan akūngge jui be ume gūnire “İş buyurduğun köleyi düşün, erdem yoksunu evladını düşünme"

boo de bifi ama eme be ginggule, goro genefi hiyan daborengge ai baita "Evde anne ve babana sayg1 göster, uzaklara gidip tütsü yakmak bunun yanında nedir?”

sain be iktambuha boo de, urunakū funcetele hūturi bi, ehe be iktambuha boo de, urunakū ambula jobolon bi "İyiliğin toplandığı bir evde her zaman fazlaca talih vardır, kötülüğün toplandığı bir evde her zaman çok talihsizlik vardır"

sargan mergen oci boo bayan akū i jalin de joborakū, jui hiyooşungga oci ama aiseme julesi facihiyaşambi “Kadın zeki ise evde zenginlik olmadığı için üzülmeye gerek yok, oğul hayırlı ise baba ne diye kaygllansın?

ama eme i bisire de, goro generakū, geneci urunakū ici be alambi "Anne ve baban hayattayken uzağa gitme, gidersen muhakkak nereye gittiğini söyle” (4:19)

juse ama eme $i$ sain ehe babe kemuni songkolome yabumbi "Çocuklar çoğunlukla anne babalarının yaptı̆̆ iyi ve kötü şeyleri tekrar ederler”

jui oci hiyooşulaci acara, deo oci deocileci acara be inu sacibe "Oğul olarak görevin ataya saygı göstermektir, kardeş olarak görevin kardeşlerine karşı sorumluluğunu yerine getirmektir”

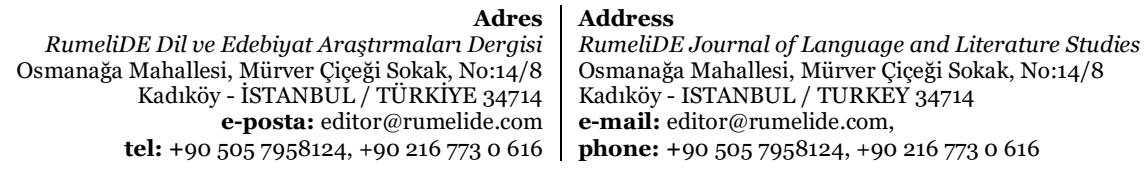




\section{Toplumsal ilişkiler ve olaylarla ilgili atasözleri}

Kişinin başkalarına karşı sorumlulukları, onlara karşı nasıl davranması gerektiğine dair uyarılar Mançu atasözlerinde ifade edilmektedir. Toplum kurallarına uymak ve toplumsal düzeni bozmamak da bu atasözlerinde vurgulanan hususlardır.

iren $i$ saişarangge be saişara, irgen i ubiyarangge be ubiyara oci, erebe irgen i ama eme sembi "İnsanların onayladığını onaylayan, karşı olduğuna karşı olan, onların annesi ve babası gibidir"

ambasa saisa niyalma i niyalma be dasambi "Bilge kişi insanları diğer insanlarla yönetir"

geren ubiyaci, urunakū kimci, geren saişaci, urunakū kimci "İnsanların onayladığı ve onaylamadı̆̆ı şeyleri iyice gözlemle"

beye, beyebe nişa, niyalma be weihuken i wakaşara oci, gasacun goro ombi "Kişi, kendisini ağır, başkalarını hafif bir şekilde eleştirirse memnuniyetsizlikler uzaklaşır"

si aika sain be yabuci, tanggū hūturi isibumbi "Sen iyilik yaparsan, yüz talih sana ulaşır"

sain be iktambuci sain $i$ karulan bi, ehe be iktambuci ehe $i$ karulan bi “İyilik yapan iyilik bulur, kötülük yapan kötülük bulur"

budai boo de funcehe buda bici, jūgun de yuyure niyalma bimbi "Mutfakta artık bir yemek varsa, yolda açlıktan ölen bir kişi vardır"

jugūn goro oci morin $i$ hūsun be sambi, inenggi goidaci niyalma mujilen be ulhimbi "Yol uzunsa atın gücü belli olur, günler geçtikçe kişinin yüreği anlaşılır” (14:33)

beyebe tob obume muterakū oci, niyalma be adarame tob obumbi "Kendini düzeltemeyen başkalarını nasıl düzeltir?” (13:22)

beye de isbure be cihakūngge be inu niyalma de ume isibure "Kendine yapılmasını istemediğini diğer kişiler de yapma” (12:2)

niyalmai ubiyarangge be saişara, niyalmai saişarangge be ubiyara oci, terebe niyalmai banin be fudarakū sembi “İnsanların onaylamadığı şeyleri övmek, övdüğü şeyleri onaylamamak insanın doğasına karşı gelmektir”

iletu şeleme bure ohode, butui baci toodame jimbi "Ulu orta sadaka verirsen, karşllı̆ğını gizli bir yerden alırsın"

sahakū bithe be hūlaci sain gucu be baha gese, hūlaha bithe be sabucife gucube acaha gese "Bilmediğin bir kitabı okumak yeni bir arkadaş edinmek gibidir, okumuş olduğun bir kitaba tekrar bakmak eski bir arkadaşı görmek gibidir"

gucuse de nure benere anggala, emu ineggi ilan jergi buda ulebu "Arkadaşlarına içki vermek yerine, günde üç kere yemek ikram et"

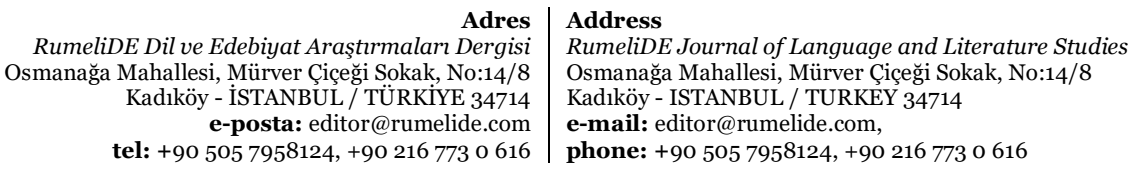


ilan niyalma emgi yabure de, urunakū musei sefu ojorongge bi "Üç kişi birlikte yürürsek, içimizden biri önderimiz olur"

asihan urse funiyehe şaraka niyalma be ume basure, ilha ilarangge hiyenakū udu udu inenggi fulgiyan ombi “Genç adam, ak saçllarla alay etme, açllan çiçekler kaç gün kızıl kalır?

ejen be weilere de dalhidaci girucun ombi, gucuse de dalhidaci aldangga ombi "Efendisine hizmet ederken ölçüsüz davranan utanır, arkadaşlarına ölçüsüz davranan yalnız kalır” (4:26)

tondo amban, juwe ejen be weilerakū, jilihangga hehe, juwe eigen be gaijirakū "Sadık bir hizmetkâr iki efendiye hizmet etmez, iffetli bir kadın iki erkekle evlenmez"

emu sain gisun de ilan tuweri halhūn adali, ehe gisun niyalma be kokiraburengge ninggun biya şahūrun gese "Tatlı bir söz üç kışı ısıtır, kötü bir söz insanları altı aylık soğuk gibi incitir"

niyalma de tusa araci, beye de tusa ombi "Başkalarına iyilik yaparsan bu kendine yaptığın iyilik olur"

irgebun i nomun i ilan tanggū fiyelen ba, emu gisun de baktambuci ombi, gūnigan miosihon akū sehe be kai “Üç yüz bölümlük şiir kitabının tek cümlelik özeti şudur; kötülük düşünme” (2:2)

etuku adu manaha erin de antaha gucu komso, niyalma be labdu takaha de uru waka labdu "Giysilerinizin yırtık olduğu günlerde eş dost az olur, çok insan tanıyınca sıkıntılar çok olur"

bi, niyalma minde isibure be cihakūngge be, bi, inu niyalma de isibure be cihaku "Ben insanların bana yapmasını istemediği şeyleri, diğer insanlara yapmak istemem" (15:24)

jalingga haha nomhon niyalma be holtome, nomhon niyalma umai sarkū be kadalara "Kötü bir adam iyi insanları aldatır, iyi insanlar cahilleri idare eder"

niyalma de emu ihan be bahaci, niyalma de emu morin be toobadu "Bir kişiden bir öküz alırsan o kişiye bir at ver"

aikabade niyalma de tusa ararakū oci, fucihi be hūlaha seme yooni untuhuri ombi "İnsanlara yararın yoksa Buda'ya yaptığın ibadetler tamamen anlamsızdır"

ini boo be tacibuci ojorakū bime, niyalma be tacibume muterengge akū "Kendi ailesini eğitemeyen başkalarını eğitemez"

maktame saişaci hūturi banjinambi, firume gisureci jobolon banjinambi "Översen talih bulursun, söversen talihsizlik bulursun”

ulin fulu oci gisun amba, hūsun etuhun oci niyalma be gidaşambi "Zenginliğin çoksa sözün ağır olur, gücün varsa insanlara tahakküm edersin"

damu sain baita be jabu, karulame acabure be ume fonjire "Sadece iyilik yap, bunun karşılığını isteme"

unenggi serengge, beye beyebe mutebure teile akū, jaka be muteburengge kai "Kâmil bir insan sadece kendisini düzeltmez, diğer insanları da düzeltir"

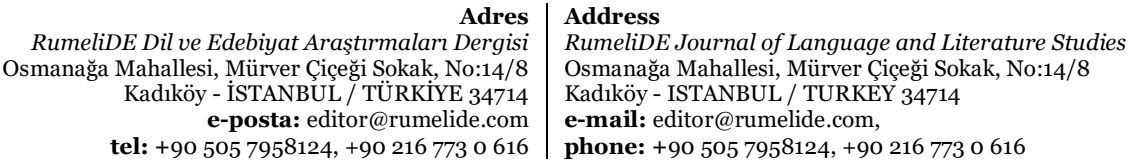

RumeliDE Dil ve Edebiyat Araştırmaları Dergis Kadıköy - İS tel: +90 505 7958124, +902167730616 
emu erinde edun, tuwa i adali jili, tuweri forgon i etuku be deijibumbi “Öfke, rüzgârlı havada ateş gibidir, kış mevsiminin kıyafetlerini yakar”

beyebe niyalma sarkū de joborakū, niyalma be sarkū de jobombi "İnsanlar beni tanımadı̆̆ı için kaygılanmam, insanları tanımadığım için kaygılanırım"

damu gosingga niyalma, niyalma be saişame mutembi, niyalma be ubiyame mutembi "Sadece sevmeyi bilen bir insan insanları övebilir ve insanlardan nefret edebilir"

foutze hendume, dele bifi onco akū, dorolon be yabure ginggūn akū sinagan de tuşafi gosihun akū oci, bi, aibe tuwambini "Efendi şöyle söyler; Yüksek bir konumda olup cömert olmayanları, ibadet ederken saygılı olmayanları, yas tutması gerektiğinde kederlenmeyenleri anlayamıyorum"

orho şahrun gecen de gelembime gecen şun de gelembi, ehe niyalma oci cisui ehe niyalma de akabumbi "Ot ayazdan korkarsa ayaz da güneşten korkar, kötü bir insanın hakkından başka bir kötü insan gelir"

sain be yaburengge de tanggū hūturi isibure, ehe be yaburengge de tanggū jobolon isibure "İyilik yapanlara yüz talih ulaşır, kötülük yapanlara yüz bela ulaşır”

gisurere jabure de urunakū dahashūn oso, tere ilire de urunakū fejile oso "Cevap verirken her zaman yumuşak başlı ol, ayağa kalkarken her zaman mütevazı ol”

ume bayan de akdafi yadahūn be fusihūşara "Zenginliğine güvenip yoksulları küçük görme”

injeci ini jalin urgunjembi, songgoci ini jalin alişambi "Gülerse onun için sevinirim, ağlarsa onun için üzülürüm”

emu niyalma turulafi geren niyalma songkoleme, emu boo yabufi gaşan, gubci alhūdame "Bir kişi ilk adımı atarsa diğerleri onu takip eder, köydeki bir aile bir şey yaparsa bütün köy onların yaptığını yapar"

beyede isirakūngge de ume gucelere "Sana denk olmayanlarla arkadaşlık etme"

jalingga haha eihen be ubaliyame, elemangga nomhon niyalma de morilabure "Kötü adamlar bir gün eşeğe dönecektir ve iyi insanlar onların sırtına binecektir"

\section{Devlet görevlileri ve devlet yönetimiyle ilgili atasözleri}

Çin'de hanedan kurmuş topluluklardan biri olan Mançular için devlet yönetimi oldukça önemli bir alandır. Yasaların önemi, devlet görevlilerinin nasıl olması gerektiği, memurun amirine karşı tutum ve sorumlulukları bazı atasözüne konu olmuştur.

niyalmai mujilen selei gese bicibe hafan i fafun hija de adali "Kişinin yüreği demir gibiyse, resmî görevlilerin buyruğu ocak gibidir"

dergingge, dorolon de amuran oci, irgen takūrabu de ja ombi “Üst mevkidekiler ibadete düşkün olursa insanları yönlendirmek kolay olur"

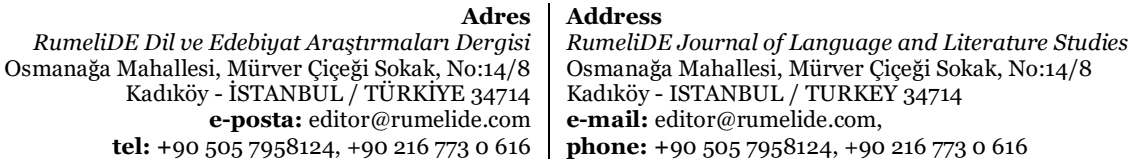


abkai jui waka oci, dorolon be gisurerakū, kemun be toktoburakū, hergen be dasarakū "Eğer göğ̈̈n oğlu ${ }^{6}$ değilseniz, ibadetten bahsedemezsiniz, kural belirleyemezsiniz, yazıyı düzeltemezsiniz"

ejen ojoro mangga, amban ojorongge ja akū sehebi "Han olmak zordur, ama onun hizmetkârı olmak kolay değildir" (13:15)

tondo amba oci bucere de gelerakū, bucere de gelere oci tondo amban waka "Sadık bir hizmetkâr ölümden korkmaz, ölümden korkuyorsa sadık bir hizmetkâr değildir”

dasan be leolembihide urunakū yoo şun be tukiyembi "Siyaset üzerinde konuşacaksak öncelikle Yao ve Şun'u7 yücelterek söze başlamalıyız"

kooli ereci sain ningge akū, gūnin ereci jiramin ningge akū "Yasadan daha önemli, düşünceden daha değerli bir şey yoktur"

dorolon $i$ nomun de henduhengge, dergi ejen be weilere de niyalma be weilere adali sehebi "Töre kitabında yazılana göre, Han'a hizmet etmek halka hizmet etmek gibidir”

hafan ujui jergide isinacibe, tumen fafun songko be dahambi "Bir görevli yüksek bir mevki sahibi olsa da bütün kurallara uymak zorundadır"

taciburakū irgen be afara de baitalaci, erebe waliyarangge sembi "Savaşta eğitimsiz kişileri kullanmak onları feda etmektir"

\section{Hayata, insana dair gözlem ve tespitlerle ilgili öğüt niteliğinde atasözleri}

Gündelik hayata dair yapılan gözlemler ve deneyimlerden çıarılan sonuçlar birçok Mançu atasözünde karşıllğını bulmuştur. Bu başlık altında verilen atasözlerinde çoğunlukla hayata dair tespitler sunularak bunlarla ilgili dolaylı veya doğrudan öğ̈̈tler verilir.

niyalma be cira tuwaci ojorakū, mederi muke be hiyase i miyalici ojorakū "İnsan görünüşüyle değerlendirilmez, deniz suyu kovayla ölçülmez"

niyalma banjirengge tanggū sede jalundarakū, kemuni minggan aniyaijobolon be hefeliyembi "İnsan yüz yaşına kadar yaşamaz ama bin yıllık sıkıntıyı bağrında taşır"

niyalma, tasha be nungnere mujilen akū tasha niyalma be nungnere mujilen bi "İnsanın kaplana zarar verme niyeti olmaz, ama kaplanın insana zarar verme niyeti olur"

golmin hiyang ni muke emgeri eyehe bolju amasi bedererakū niyalma sakdaka manggi ainahai dahūme asihan ojorongge "Irmağın suyu bir kere aktıktan sonra geriye dönmez, insan yaşlandıktan sonra tekrar genç olmaz”

niyalma, aisi be sabuha gojime jobolon be saburakū, nimaha, be be sabuha gojime welmiyeku be saburakū "İnsan talihi kovalar, talihsizliği değil, balık yemi kovalar, kancayı değil"

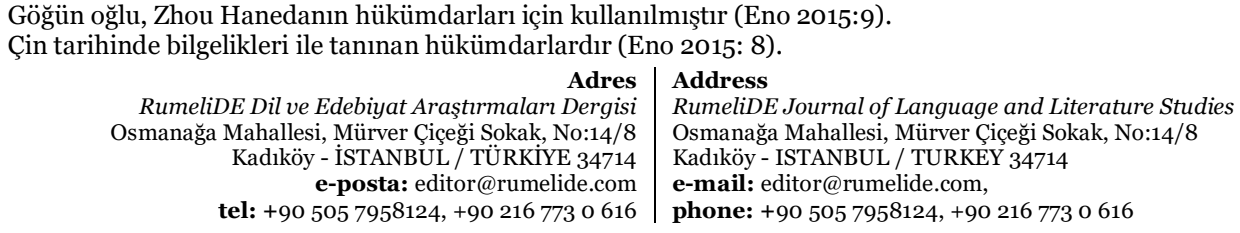


ibtenehe moo be colici ojorakū, hukun boihon i fajiran be ilbaci ojorakū "Çürümüş bir tahtayı oyamazsın, gübre ve çamurla duvarı sıvayamazsın" (5:10)

manju gisun nikan gisun ci ja "Mançu dili Çin dilinden kolaydır"

manju bithe be urunakū urebu, akūci nikan bithe be hafukiyame getukeleme mutembio "Mançu yazısını kesinlikle çalış, yoksa Çin yazısını ayrıntılarıyla açıklayabilir misin?”

manju gisun i ududu hergen be nikan niyalma hūlame muteraku "Mançu dilinin çok heceli kelimelerini Çinliler telaffuz edemez"

udu enduringge seme, inu muterakū babi "Kişi ne kadar yüce olursa olsun yapamayacağı şeyler vardır" hūturijobolon de duka akū, damu niyalmai beye baimbi "Talih ve talihsizliğe açılan kapı yoktur, ancak kişinin kendisi bunları arayarak bulur”

wesihun bahacibe girucun be gūni, beye elhe oci suilacun be gūni "Haysiyet kazanırsan utancı düşün, bedenin sağlıklıysa hastalığı düşün”

jaka de da dube bi, baita de tuhen deribun bi "Her şeyin kökeni ve sonu vardır, her işin bir sonucu ve başlangıcı vardır"

niyalma de goro seolen akū oci, urunakū hanci jobocun bi "Kişi uzaktaki şeylere karşı düşüncesizse, sıkıntıları yakınında bulması kaçınılmazdır"

horonggo tasha jugūn i dulimbi de dedurakū, horibuha, muduri inu abka wesire erin bi "Kaplan yolun ortasında yatmaz, tutsak bir ejderha zamanı gelince göğe yükselir"

niyalma de tafulara ilan hacin i amba doro bi, nure be targa, boco be aldangga, jiha be ume efire "İnsanlara ögütlenecek üç önemli kural vardır; İçkiden kaçının, şehvete kapılmayın, kumar oynamayın”

ilan aniya otolo tacici, fulun be gūnirakūngge be, ja de baharakū kai “ Üç yll okuyup, kazancını düşünmeyen birini bulmak kolay değildir"

emu morin juwe anggemu be tohorakū, tondo amban juwe ejen be weilerakū "Bir ata iki eyer vurulmaz, sadık bir hizmetkâr iki efendiye hizmet etmez"

muwa buda jeme, muke omime, gala bukdame cirucibe sebjen inu terei dolo bi "Çiğ aş yemek, su içmek, ellerini bağlayarak boyun eğmek, bunlarda bile bir sevinç vardır”

ilha de dahūme ilara erin bi niyalma de enteheme asihan ojorongge akū "Çiçeklerin tekrar açllacağı bir mevsim vardır, fakat insan hiçbir zaman tekrar genç olamaz"

sunja ciktan be dahaci, mujilen tani tob ombi "Her kim beş ilkeye uyarsa, niyeti hep iyidir"

gosire de, suilaburakū ome mutembio tondo de jomburakū ome mutembio "Sevenin acı çekmemesi, âdil olanın itiraz etmemesi mümkün mü?

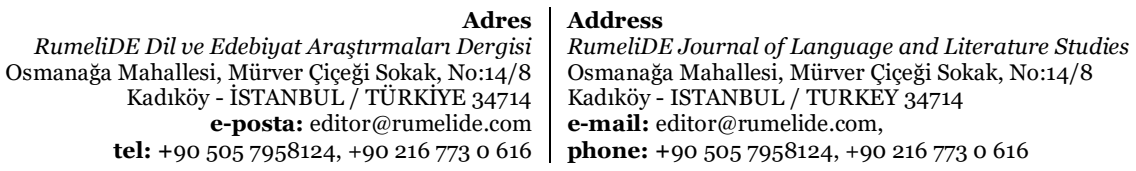


niyalma bime gosin akū oci, dorolon be ainara, niyalma bime gosin akū oci, kumun be ainara "Kişinin insaniyeti yoksa ibadetle ne işi olur, kişinin insaniyeti yoksa müzikle ne işi olur" (3:3)

niyalma omirakū jeterakūngge akū, amtan be same bahanarangge komso sembihe "Yemeyen ve içmeyen bir kişi yoktur, ancak çok az kişinin iyi bir damak tadı vardır” (17:19)

abka na i amba seme, niyalma hono gasara babi "Yer ve gök ne kadar geniş olsa da insan şikâyet edecek bir şey bulur"

niyalma i kidure gūnirengge cira boco akū "Kişinin isteklerinin ve düşüncelerinin şekli ve rengi yoktur" mujilen dolo daldarakū oci, tumen hacin yooni getuken ombi "Yüreğindekileri gizlemezsen her şey sana aşikâr olur"

hesebun sain oci niyalma, hutu be gelembumbi, forgon wasika manggi hutu inu necinjimbi "Kişinin kaderinin iyi olması kötü ruhları korkutur, zamanı azaldıktan sonra kötü ruhlar saldırıya geçer"

nure be komsokon i omi, baita be fulukan i ulhi "Az içki içerek her şeyi daha çok anla"

yadahūn bime haldaba akū, bayan bime cokto akungge, antaka "Yoksul olup dalkavuk olmayan, zengin olup mağrur olmayan var mı?” (1:15)

gisurere de girurakū oci, yabure de mangga ombi "Çekinerek söylediğini zorlanarak yaparsın” (12:3)

niyalma ulin i jalin de bucembi, gasha be i jalin de gaibumbi “İnsan mal mülk uğruna ölür, kuş yem uğruna yok olur"

abka de ïishūn ningge taksimbi, abka de fudasihūn ningge gukumbi "Tanrıya itaat eden kendini bulur, Tanrıya asi olan kendini kaybeder"

abka, niyalma be ujire gung bicibe, niyalma, abka de karulan husūn akū "Tanrı insana rızk verse de insan Tanrıya bunun karşıllı̆ını vermekten yoksundur"

şun mukdefi alin i miyoo hūwaşasa ilire unde, bodoci gebu aisi sere anggala jirgara de isirakū "Güneş doğduktan sonra dağdaki mabedin keşişleri kalkmadıysa, kendi nasibini düşünerek rahatını bozma”

yadahūn bime gasarakūngge mangga, bayan bime coktolorakūngge ja "Yoksul olup kıskanç olmamak zordur, zengin olup mağrur olmamak kolaydır” (14:10)

dorolon de mamgiyara anggala, hibcan ocina, sinagan de, yangselara anggala gosihon ocina “İbadette aşırıya kaçmak yerine ölçülü ol, yas tutarken iyi görünmek yerine acılı ol” (19:14)

gasha bucere hamime, terei guwenderengge usacuka, niyalma bucere hamime, terei gisun sain "Kuş ölüme yaklaşırken ötüşü hüzünlü olur, kişi ölüme yaklaşırken sözü iyi olur”

mujilen sain oci boo de wesihun jui banjimbi, forgon sain oci aiseme mafa i usin de akdambi "Niyet iyi ise evde yüce bir oğul doğar, mevsim iyi ise neden atalarının tarlasına güvenmezsin?”

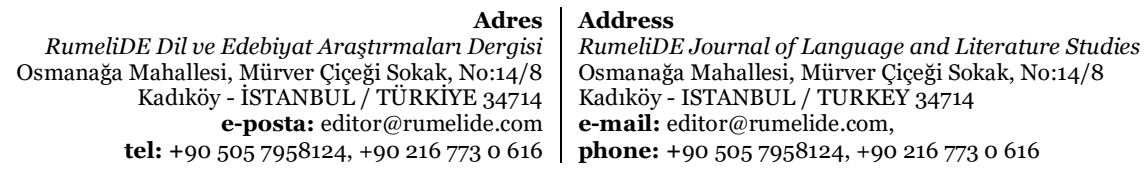


bi tuwaci ududu boo yadafi geli bayakabi, ududu boo bayafi dahūme yadahūn ohobi "Fakirken zengin olan, zenginken tekrar fakir olan birçok ev gördüm”

yaya jugūn de yabure urse, gemu encu gaşan i niyalma "Yolda yürüyen kişilerin hepsinin köyü farklı" dulekengge be jabcaci ojorakū oho,jiterengge be kemuni tosoci ombi "Olana hayıflanmak olmaz, olacak olana hazırlanmak gerek"

geren cooha de jiyanggiyun be durici ombi, emteli haha de mujin be durici ojoraku "Ordudan bir generali ele geçirebilirsin, yalnız bir adamın heveslerini ele geçiremezsin" (9:26)

tarire ihan nememe jetere orho akū, zang ni singeri elemangga funcetele jeku bi "Tarlayı süren öküzün yiyecek otu yokken bir farenin çokça yiyeceği vardır”

mutere muterakū babe fonjici ombi "Olabilecek ve olamayacak şeyleri sorabiliriz"

ulin bisire urse gisun be sume mutembi, ulin akū niyalma gisun be donjirakū "Varlıklı kişiler sözlerini anlatabilir, yoksul kişilerin sözleri duyulmaz"

niyalma de minggan inenggi sain akū, ilha fataha manggi fulgiyan boco gūwaliyambi "İnsan bin güzel gün geçirmediyse, çiçekleri yolunmuş ve kızıl rengi solmuş gibidir"

forgon genehe manggi suwayan aisin i boco gūwaliyambi, erin isinjaha de sele inu eldeme jergişeme "Zamanı bittikten sonra altının rengi solar, zamanı gelince demir ışıldayarak parlar"

morin, yarfun be tuhebure baili bi, indahūn, orho be usihibure karulan bi "Yularını çıarmak ata iyiliktir, çimi ıslatmak köpeğe cezadır"

niyalma, da baci aljaha de fusihūn, jaka, da baci aljaha de wesihun "Yabancı bir yerden gelen kişi değersizdir, yabancı bir yerden gelen eşya ise değerlidir"

orho dorgi be gisureci, jakūnde jabure niyalma donjimbi sehebi "Çayırın ortasında konuşursan yoldan geçenler seni duyar"

gisun labdu oci gisurere de ufarambi, labdu jehe manggi dolo alişambi "Sözün çok olursa konuşurken yanılırsın, çok yemek yedikten sonra miden rahatsızlanır"

jiha bici uthai baitala, bucehe manggi gemu untuhuri ombi "Paran varsa harca, öldükten sonra her şey boş olur"

baita tome dabtame seoleci, amaga inenggi aliyacun bahafi guwembi "Yapacağın her şeyi uzun uzun düşünürsen, gelecekte yaşayacağın pişmanlıklardan kurtulursun” (2:18)

sain ehe ningge be ilgaburakū oci, bireme gemu sain seci geli ombio "İyi ve kötü şeyler ayırt edilemediğinde her şeye iyi demek mümkün mü?”

mergengge urse muke be buyembi, gosingga urse alin be buyembi "Bilge kişiler denizi sever, sevecen kişiler dağı sever" (6:23)

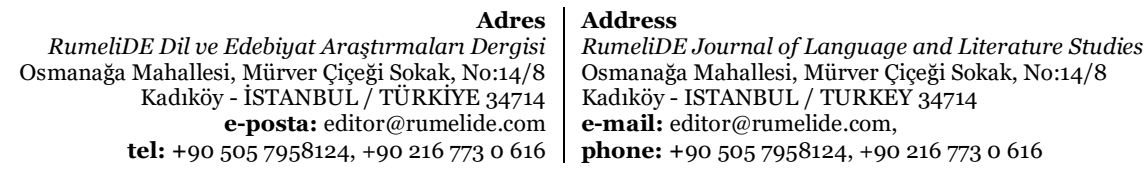


bucere banjirengge emu erin i andande bi “Ölmek ve doğmak sadece bir an meselesidir”

niyalma banjïr de emu inenggi seme baitalan akū obume muterakū, uthai emu inenggi seme ulin akū oci ojoraku "İnsan hayatında ihtiyaçlarını karşılamadan yaşayamaz, bu yüzden rızkının peşinde olmadığı bir gün yoktur”

gosingga be yabuci bayan ume muterakū, bayan oki seci gosingga de ojorakū "Sevgi dolu bir insan zenginlik peşinde koşmaz, zengin olmak isteyen sevgi dolu bir insan değildir”

baita amala amcame aliyara anggala an i ucuri ciralame tacibure de isiraku "Olanın ardından ağlamak yerine anın firsatını değerlendirmek daha iyidir”

honin deberen udu amtangga bicibe geren i angga de acaburengge mangga "Koyun etinin tadı güzel olsa da, herkesin bunu sevmesini beklemek zordur"

niyalma yadahūn oci gūnin foholon, morin turga oci funiyehe golmin "Bir kişi yoksulsa fikri kısadır, bir at zayıfsa yelesi uzundur"

haksan be yabume jabşan be baire anggala, necin de tefi hesebun be aliyara de isirakū "Acele davranarak talihini aramak yerine sükûnet içinde oturup kaderini beklemek iyidir”

galga inenggi muke eyere ko sangga be dasata, hūwanggar seme agara de belhembi "Açık bir günde suyun akıp gideceği yolları düzenlemek gerekir, bu firtınalara hazırlıktı»"

sarangge, amūrangge de isirakū, amurangge sebjelerengge de isiraku "Bir şeyi bilen o şeyi sevene yaklaşmaz, bir şeyi seven o şeyden keyif alana yaklaşmaz"

manjusiri fucihe terei bade baci, geren ergengge teisu be bahambi "Buda Manjusiri bu dünyadaysa bütün canlılar ihtiyaçlarını elde edecekler"

niyalma necin oci gisurerakū, muke necin oci eyerakū "İnsan huzur içindeyse konuşmaz, su huzur içindeyse akmaz"

tacihai şungke bime niyalma kemuni sarkū "Ne kadar öğrense de insanın hâlâ bilmediği şeyler vardır"

gosingga urse joboşorakū, mergengge urse hūlimburakū, baturungga urse golorakū "Sevgi dolu bir insan kaygllanmaz, akıllı bir insan aldanmaz, cesur insan korkmaz" (9:29)

\section{Sonuç}

Mançu atasözleri konularına göre incelendiğinde bunların bilginin ve bilgeliğin önemi, aile ve aile bireyleri arasındaki ilişkiler, toplumsal ilişkiler ve devlet yönetimi ile ilgili olduğu görülmektedir. Ayrıca hayatla ilgili tespit ve öğüt niteliği taşıyan birçok atasözü de dikkat çekmektedir. Bunlardan bilgi ve bilgeliğin önemine dair olan atasözlerinin önemli bir kısmı Konfüçyüs’ün özlü sözlerinin Mançucaya çevirisidir:

erde doro be donjifi, yamji bucecibe ombikai "Sabah doğruyu duyduktan sonra akşam ölsem de gam yemem" (4:8)

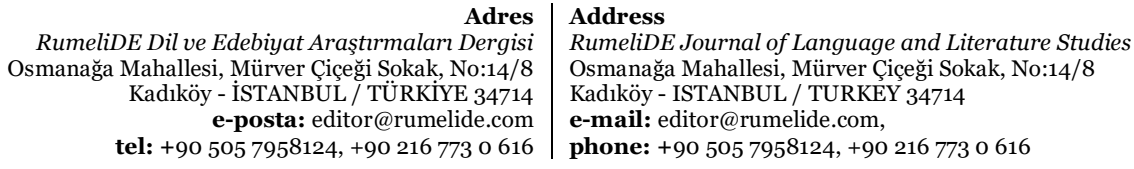


ambasa saisa mohocibe akdun, buya niyalma mohoci, uthai balai ombi "Bilge kişiler yokluğa düşse de sağlam durur, sıradan kişiler yokluğa düşse hemen bozulur” (15:2)

ambasa saisa beye de baimbi, buyu niyalma, beye de baimbi "Bilge kişiler kendini sorgular, sıradan kişiler başkalarını sorgular" (15:21)

Bununla birlikte gündelik hayatla ilgili gözlem ve deneyimlere dayanan atasözlerinin büyük bir bölümünün aslî olarak Mançu kültürüne ait olduğunu söylemek mümkündür.

honin deberen udu amtangga bicibe geren $i$ angga de acaburengge mangga "Koyun etinin tadı güzel olsa da, herkesin bunu sevmesini beklemek zordur"

emu sain gisun de ilan tuweri halhūn adali, ehe gisun niyalma be kokiraburengge ninggun biya şahūrun gese "Tatlı bir söz üç kışı ısıtır, kötü bir söz insanları altı aylık soğuk gibi incitir"

Sözlü kültür ürünleri olan atasözlerinin akılda daha kalıcı olması birtakım ses tekrarları, anlam bakımından koşutluklar ve zıtlıklar ile sağlanır. Mançu atasözlerinin yapısında da birçok ses tekrarı, anlamsal koşutluklar ve zıtlıklar dikkat çeker. Aliterasyon, tezat ve tenasüp sanatları Türk atasözlerinde de sıklıkla görülmektedir (Çobanoğlu 2004: 25-26).

Şu atasözlerinde /s/, /b/, /d/ ve /j/ seslerinin tekrar edildiği görülür:

ambasa saisa beye de baimbi, buyu niyalma, beye de baimbi "Bilge kişiler kendini sorgular, sıradan kişiler başkalarını sorgular” (15:21)

bi tuwaci ududu boo yadafi geli bayakabi, ududu boo bayafi dahūme yadahūn ohobi "Fakirken zengin olan, zenginken tekrar fakir olan birçok ev gördüm"

tondo amban, juwe ejen be weilerakū, jilihangga hehe, juwe eigen be gaijirakū "Sadık bir hizmetkâr iki efendiye hizmet etmez, iffetli bir kadın iki erkekle evlenmez"

Aşağıda verilen Mançu atasözlerinin yapısında ise anlam bakımından koşut ve zıt kelimeler bulunmaktadır:

nure be komsokon i omi, baita be fulukan i ulhi "Az içki içerek her şeyi daha çok anla"

emu sain gisun de ilan tuweri halhūn adali, ehe gisun niyalma be kokiraburengge ninggun biya şahūrun gese "Tatlı bir söz üç kışı ısıtır, kötü bir söz insanları altı aylık soğuk gibi incitir"

niyalma yadahūn oci gūnin foholon, morin turga oci funiyehe golmin "Bir kişi yoksulsa fikri kısadır, bir at zayıfsa yelesi uzundur"

sain be iktambuci sain $i$ karulan bi, ehe be iktambuci ehe $i$ karulan bi "İyilik yapan iyilik bulur, kötü̈lük yapan kötülük bulur"

niyalma de tusa araci, beye de tusa ombi "Başkalarına iyilik yaparsan bu kendine yaptığın iyilik olur"

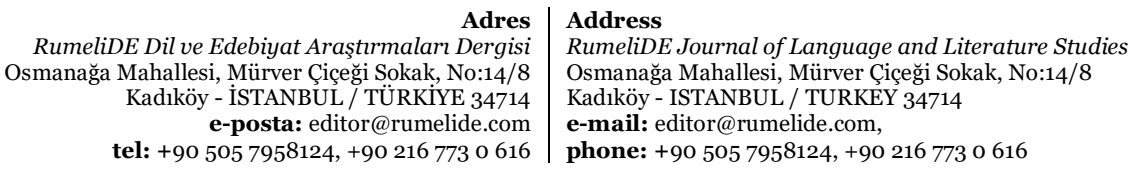


tacire de amurangge, mergen de hanci, girure be sarangge, baturu de hanci "Öğrenmeyi seven bilginlere yakındır, utanmayı bilen cesurlara yakındır"

gisun labdu oci gisurere de ufarambi, labdu jehe manggi dolo alişambi "Sözün çok olursa konuşurken yanılırsın, çok yemek yedikten sonra miden rahatsızlanır"

sarangge, amūrangge de isirakū, amurangge sebjelerengge de isirakū "Bir şeyi bilen o şeyi sevene yaklaşmaz, bir şeyi seven o şeyden keyif alana yaklaşmaz”

"Altay dilleri” konuşan halkların atasözleri üzerine yapılacak geniş kapsamlı ve karşılaştırmalı araştırmalar, bu halkların arasındaki ilişkinin niteliğinin daha iyi anlaşılması için önemli veriler sunacaktır.

\section{Kaynakça}

Aksoy, Ö. A. (1971). Atasözleri ve Deyimler. Ankara: TDK.

Crossley, P. K. (1990). Orphan Warriors : Three Manchu Generations and the End of the Qing World . Princeton, N.J: Princeton University Press.

Çobanoğlu, Ö. (2004). Türk Dünyası Ortak Atasözleri Sözlüğü. Ankara: Atatürk Kültür Merkezi Başkanlı̆̆

Durmuş, O. (2020). Türkçenin Basıl İlk Atasözü Kitabı: G.B. Donado’nun Derlediği Türk Atasözleri, Ankara: Türk Kültürünü Araştırma Enstitüsü.

Elliot, Mark C. (2001). The Manchu Way: The Eight Banners and Ethnic Identity in Late Imperial China. Stanford (CA): Stanford University Press.

Eno, R. (2015). The Analects of Confucius An online Teaching Translation. https://chinatxt.sitehost.iu.edu/Analects_of_Confucius_(Eno-2015).pdf [Erişim Tarihi: 15.12.2021].

Gorelova, L. M. (2002). Manchu Grammar. Leiden: Brill.

Gül, B. (2010). Moğol Atasözleri. Ankara: Türk Kültürünü Araştırma Enstitüsü.

Hauer, E., Corff, O. (2007). Handwörterbuch der Mandschusprache. Wiesbaden: Harrassowitz.

Janhunen, J. (1996). Manchuria: an Ethnic History. Helsinki: Finno-Ugrian Society.

Janhunen, J. (2005). Tungusic: An Endangered Language Family in Northeast Asia. International Journal of The Sociology of Language 173, 37-54.

Lee, Y. T. (2017). Kore Atasözlerinin Mukayeseli İncelenmesi. Yayımlanmamış Yüksek Lisans Tezi, Ankara: Hacettepe Üniversitesi, Türkiyat Araştırmaları Enstitüsü.

Meider, W. (2004). Proverbs a Handbook. London: Greenwood Press.

von Möllendorff, P.G. (1890). “Essays on Manchu Literature.” Journal of the China Branch of the Royal Asiatic Society. 24-25: 1-45

Norman, J. (2003). "The Manchus and Their Language (Presidential Address)". Journal of the American Oriental Society 123, 483-491.

Norman, J. (2013). A comprehensive Manchu-English dictionary. Cambridge, London: Harvard University Asia Centre.

Rachewiltz, I. de ve Rybatzki, V. (2010). Introduction to Altaic Philology : Turkic, Mongolian, Manchu. Leiden: Brill.

Rochet, L. (1875). Sentences, maximes et proverbes mantchoux et mongols, Paris.

Stary, G. (1986). “Mandschurische Geflügelte Worte.” Ural-altaische Jahrbücher N F 6, 153-183.

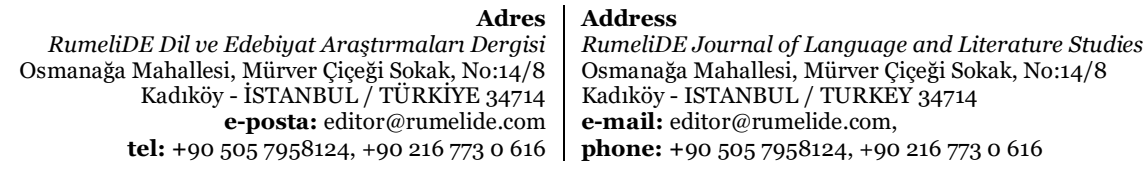


Stary, G. (1987). “A New Subdivision of Manchu Literature: Some Proposals.” Central Asiatic Journal, 31(3/4), 287-296.

Stary, G. (1990). "A new Altaistic Science: "Nishanology"”. Proceedings of the 32nd Meeting of the Permanent International Altaistic Conference içinde, Oslo: Universitetsforlaget.

Stary, G. (1994). Disappearance and Survival of a Dominant Nation: the Mancu Case. The East and the Meaning of History içinde. Roma: Bardi (Studi Orientali 13). 469-479.

Stary, G. (2002). "The 'Discovery' of Manchu Literature and Its Problems." The First International Conference on Manchu-Tungus Studies içinde. Wiesbaden: Harrassowitz, 165-178.

Stary, G. (2005). What's where in manchu literature. Wiesbaden: Harrassowitz.

Stary, G. (2012). "Flying Words- A Manchu Variant of European Winged Words?” RAN Institut lingvistiçeskikh issledovanij: Varietas delectans. Sbornik statej k 70-letiju Nikolaja Leonidoviça Sukhaçeva, Sankt Petersburg: Nestor-Istorija, 502-509.

RumeliDE Dil ve Edebiyat Araştırmaları Dergisi Osmanağa Mahallesi, Mürver Çiçeği Sokak, No:14/8 Kadıköy - İSTANBUL / TÜRKIYE 34714 e-posta: editor@rumelide.com tel: +90 $5057958124,+902167730616$
Address

RumeliDE Journal of Language and Literature Studies Osmanağa Mahallesi, Mürver Çiçeği Sokak, No:14/8

Kadıköy - ISTANBUL / TURKEY 34714

e-mail: editor@rumelide.com,

phone: +90 505 7958124, +90 2167730616 